\title{
Design of the clamping system for the CNC machine tool
}

\author{
Miroslav Císar ${ }^{1, *}$, Ivan Kuric ${ }^{1}$, Nadežda Čuboňová ${ }^{1}$, and Matej Kandera ${ }^{1}$ \\ ${ }^{1}$ University of Žilina, Faculty of Mechanical Engineering, Department of Automation and Production \\ Systems, Univerzitná 1, 01026 Žilina, Slovakia
}

\begin{abstract}
The workpiece clamping and system for automatic workpiece exchange are still topics of great importance. This article describes design of such system implementing interchangeable technological pallets for laboratory training $\mathrm{CNC}$ machine tool with confined workspace and limited lengths of feeds. Final design described in article is suitable for implementation in laboratory but also for industrial usage.
\end{abstract}

\section{Introduction}

The workpiece clamping is essential part of machining regardless if it is done on conventional machine tools or numerically controlled ones. The time necessary to properly clamp, align, and set up the stock can significantly affect production especially for parts with short cycle times. The approach, relatively common especially in mass production is implementation of technological pallet that host workpieces what allows to parallelize processes of clamping, aligning, and machining itself. Technological pallets are inalienable part of flexible manufacturing systems (FMS) and their implementation, beside time savings and increased potential for automation, it is also capable of promoting further benefits such as greater variability of available mounting systems, increased flexibility in production switching, increased repeatability, and lot more [1].

The systems of technological pallets can utilize various systems for aligning and mounting that should allow fast and simple exchange of individual pallets regardless it is done manually or by automatic pallet exchange system. Each system has its own pros and cons and it is important to choose right one for specific application considering technical and economic aspects [1].

Unfortunately, even pallet systems have downsides and limitations that can negatively affect production, which have to be carefully considered. This article presents design of interchangeable technological pallet system for CNC machine tool Emco Concept Mill 105 (CM 105) - small milling machine with three controlled axis designed specifically for industrial training which is available in laboratory of CNC programing at the Department of Automation and Production Systems, Faculty of mechanical engineering, University of Zilina $[1,2]$.

\footnotetext{
*Corresponding author: miroslav.cisar@fstroj.uniza.sk
} 


\section{The initial design conditions}

The design of proposed pallet system is focused to be compatible with Emco CM 105, what is compact machine tool designed for industrial training and educational purposes. Such machine tools are commonly used at technical high schools and universities. Tools are stored in ten station turret and therefor even unused tools can sometimes overlap to workspace. Slides and load-bearing elements of this machine are made of gray cast iron. The machine tool is already equipped with electronic and mechanic necessities preparation to implement higher level of automation. Standard milling vise with $60 \mathrm{~mm}$ jaw opening or mill clamps are currently used for workpiece clamping [1].

There is no ready to use commercially available pallet system compatible with this machine tool therefor it was necessary to design custom one. In order to implement system of automatic workpiece exchange, not only manually operated exchange of pallets, it is necessary to add optional accessories such as pneumatic unit, mechanism for automatic door operation and source of compressed air. Further improvement of workplace to implement principles of computer integrated manufacturing (CIM) even to level of FMS would need adding Robotik-Interface hardware and software together with DNC-Interface [2-4].

Proposed design had to take account of the limiting parameters of the machine tool listed in table 1 and also following basic requirements:

- the design shall allow automated and manual workpiece exchange,

- it should allow implementing of various clamping systems,

- overall height should be minimal in order to minimize restrains of workspace,

- the construction should be as simple as possible,

- the pallet system have to withstand maximal possible loads with minimal deformations.

Table 1 The parameters of machine tool relevant to design of pallet system [3].

\begin{tabular}{|l|c|c|}
\hline Travel per axis $(\mathrm{X} \times \mathrm{Y} \times \mathrm{Z})$ & {$[\mathrm{mm}]$} & $200 \times 150 \times 250$ \\
\hline Effective Z-stoke & {$[\mathrm{mm}]$} & 150 \\
\hline Distance spindle nose - table surface & {$[\mathrm{mm}]$} & $95 \div 245$ \\
\hline Clamping surface $(\mathrm{L} \times \mathrm{W})$ & {$[\mathrm{mm}]$} & $420 \times 125$ \\
\hline Maximum table load & {$[\mathrm{kg}]$} & 10 \\
\hline 2 T-slots acc. To DIN 650 & {$[\mathrm{mm}]$} & 11 \\
\hline T-slots distance & {$[\mathrm{mm}]$} & 90 \\
\hline
\end{tabular}

\section{Design of clamping system}

Based on requirements described in chapter above, two distinct designs were created. One of the designs is focused to be fully automatable and fully compatible with other parts of planed FMS. The second design is simpler and designed to be manually operated but it does not require upgrades of systems of machine tool and therefor it can be implemented in case that the project of FMS will not be realized in which case such clamping system still can provide great addition to usability of machine tool in terms of educational potential.

The proposed designs are relatively similar from view of the shape off pallet but with different system of pallet mounting. The common construction of pallet systems uses flat pallets and single piece mounting base that rises pallet by the sum of thicknesses of individual elements. Innovative non-flat shape of pallet with raised ends minimizes workspace limitation due overall thickness of system as it moves mounting and centering elements to the sides. Therefor both proposed designs reduces usable workspace in direction of Z-axis only by thickness of the pallet. 
The first design (Fig. 1) is focused to allow fully automated exchange and utilizes zero-point fixture system which is high standard in industry. The zero-point fixtures provide both alignment and mounting of the pallet in wokspace [2, 5-7].

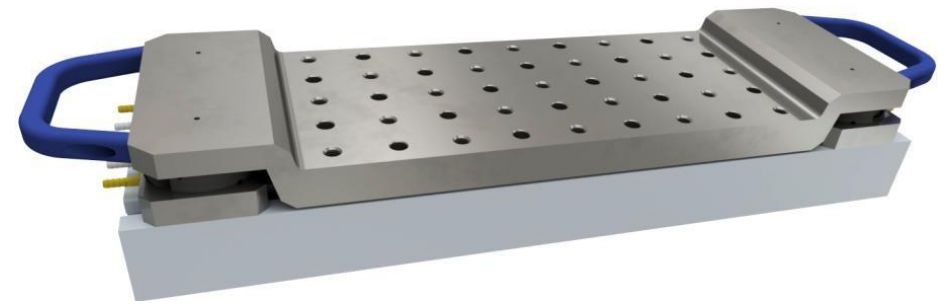

Fig. 1. Pallet system with zero-point fixtures.

The second one (Fig. 2) is simpler and cheaper, it uses manually operated levers with helical surfaces to generate mounting force. The position of pallet on mounting base is ensured by taper pins fitted with housing drilled into pallet [5].

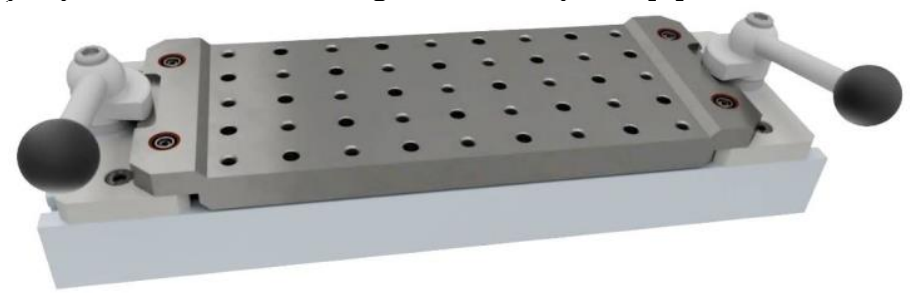

Fig. 2. Pallet system with manually operated levers.

Both proposed designs of clamping system are based on pallet system approach and therefor their construction can be divided into following three construction nodes:

- Mounting base - clamped on worktable, ensures position of mounted pallet in workspace.

- Mounting mechanism - performs safe pallet mounting and releasing.

- Pallet - interchangeable part fitted with geometrical elements necessary for selected clamping system (T-slots, set of holes, threaded holes, etc.)

\subsection{Mounting base}

Normally, the mounting plate is single piece of metal (baseplate) sheet fitted with mounting mechanism, in this case it was divided to two identical sections in order to minimize height of clamping system and reduce its negative impact to size of effective workspace of machine tool. Both types of baseplates can be mounted on worktable using Allan screws and T-slot nuts as shown on Fig. 3. The proper alignment with direction of axes of machine tool can be reached by using common tool spacer, and dial indicator or a touch probe.
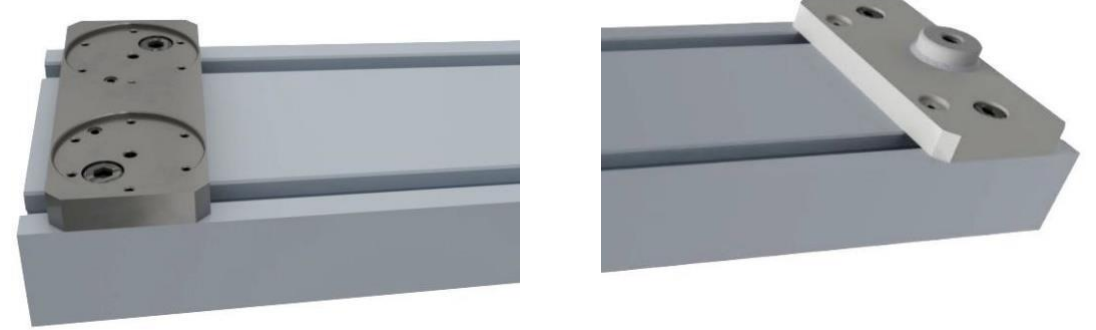

Fig. 3. Divided base plates for zero-point system (left) and lever system (right). 
The screws on baseplate for zero-point system (Fig. 3 left) are located in cavity that assure position off zero-point units and thus mounting of such baseplate will take slightly longer time as it is necessary to mount it on worktable and assemble system afterwards. The baseplate also contains holes for distribution of compressed air necessary to operate zeropoint fixtures.

The mounting base for the second proposed system (Fig. 3 right) is designed as weldment in order to reduce material requirements. The tapper pins have to be mounted only after the baseplates are mounted to work table and the pallet have to be used to align them properly.

\subsection{Mounting mechanism}

So-called zero-point fixture system as relatively new trend in fixture market offers easy way to reliably hold pallets where the fixtures have been previously assembled and verified. The clamping system assures that, as the pallets are changed, the fixtures and parts does not need to be realigned to guarantee its correct positioning. Hence, they provide constant zero point with no need of realignment between the pallet and worktable as well as a rapid and safe mounting, exchange, and release of the pallets.

The zero-point fixtures are pneumatically operated what allows to control releasing of pallet by pneumatic unit and standard machine tool interface that is normally used to release workpiece from pneumatic vice as optional equipment provided by Emco.

The first design uses four zero-point fixtures, two on each mounting base as shown on Fig. 4. Each zero-point is mounted to mounting base by six Allen screws and equipped with rubber O-rings to ensure airtight connection to pneumatic system. The fixtures have to be assembled after mounting base plate to worktable.

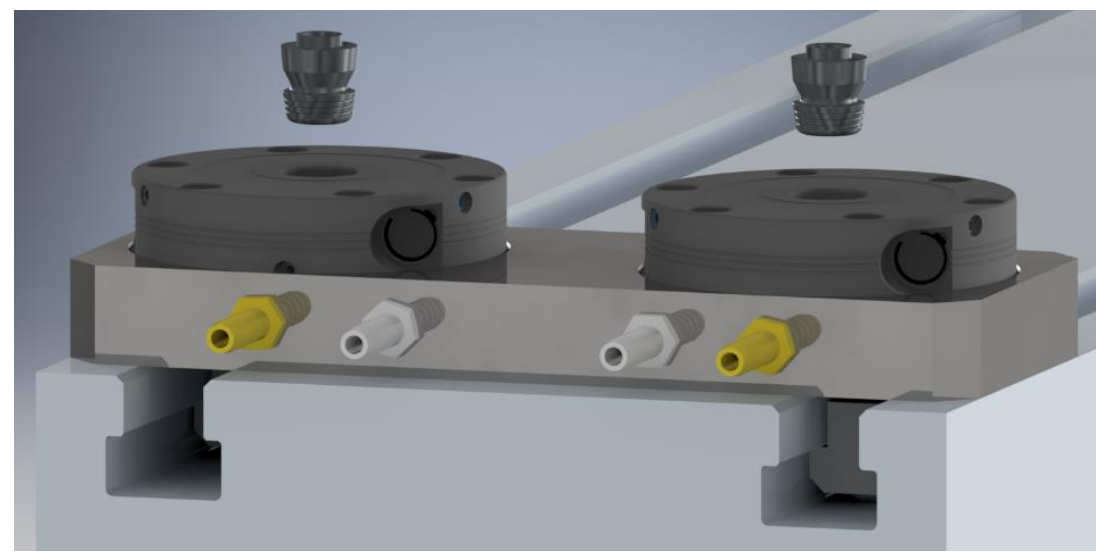

Fig. 4. Mounting mechanism with zero-point fixtures

The pallet stoppers (the pins that fits into zero-point fixture) are mounted to pallet by double ended round collar machine screws with hex recess for Allen wrench. Such mounting allows to set exact position of pallet stoppers on pallet, to align pallet with directions of axes of machine tool, to assemble whole pallet system without necessity to modify standard pallet stoppers.

The second design (Fig. 2) uses more common approach to alignment and mounting of pallet - the taper pins fitted with housing drilled into pallet, that ensures correct position and orientation of pallet, combined with manually operated levers with helical surface that generate clamping force by turning. The levers (Fig. 5 left) are made by Halder Inc. If it will be reasonable to automate releasing of pallet with this system the levers can be replaced by component with same helical shape and size driven by appropriate stepper motors. 
In this case, the correct position is ensured by four centering pins (Fig. 5 center) mounted to base by Allen screws, paired with bronze housing (Fig. 5 right) fitted to pallet. The centering pins should be mounted to mounting base through housing in pallet in order to set right position and ensure loosen fit that allows comfortable exchange of pallet.
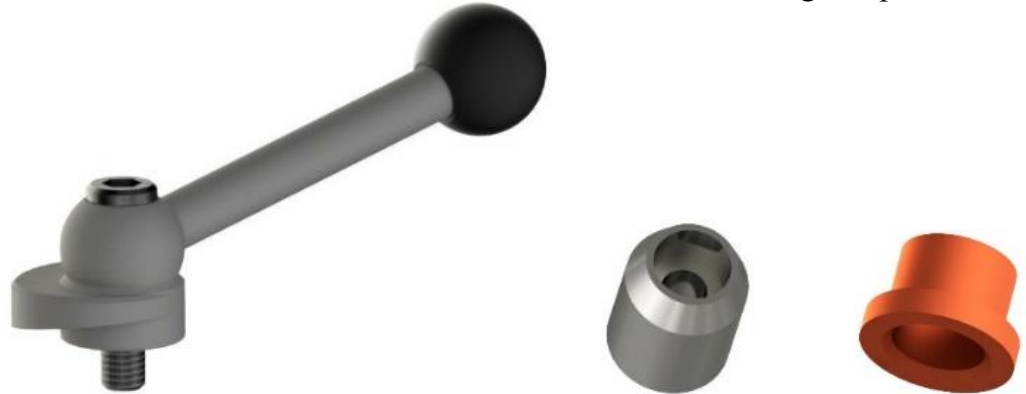

Fig. 5. The mounting lever (left) centering pin (center), and centering housing (right)

\subsection{The pallet}

Hence, the both proposed designs use mounting base divided to two sections, the general shape of pallet is very similar as shown on Fig. 1 and Fig. 2. The pallet system allow to use various types of clamping systems and mechanisms such as T-slots, grid of holes, grid of threaded holes. For purposes of this article the combination of holes and threaded holes as shown on schematic Fig. 6 was selected as it is compatible with multiple modular fixture systems and it can be used as example of advanced workpiece clamping systems compared to vice commonly used with such machine tools. The machine tool Emco CM 105 is used for educational purposes and the pallet system should widen its educational potential.

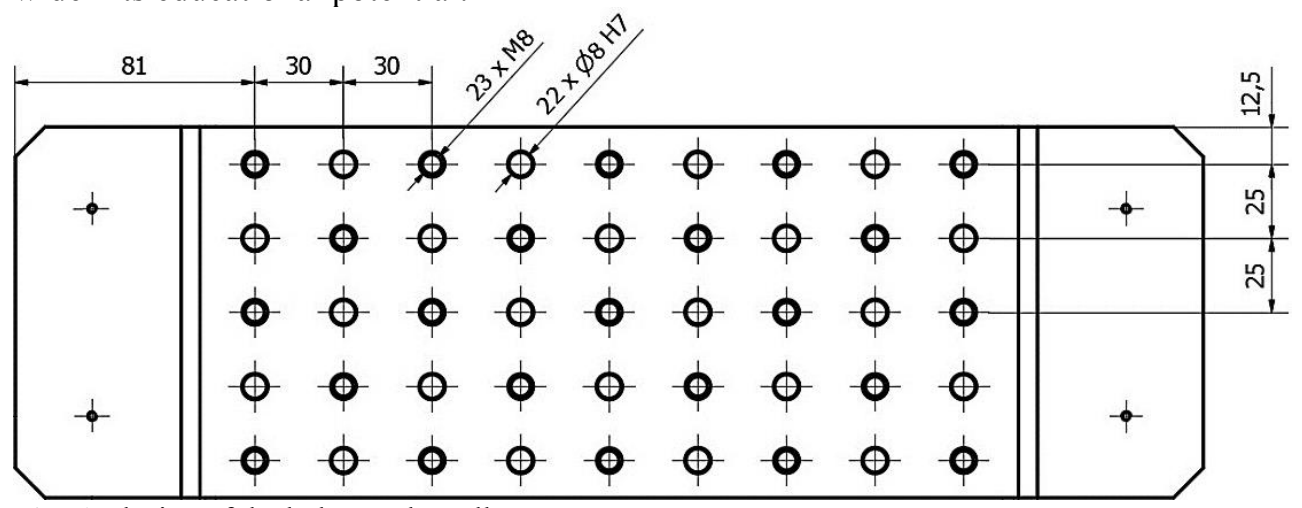

Fig. 6. Placing of the holes on the pallet

In order to allow manipulate pallet by hand the handles have to be added. Simple handle for the first design is on the Fig. 7 (left) and it is also visible mounted on pallet at Fig. 1.

The second design requires different design of handles as the levers would collide with handles. In this case it is possible to use detachable handles (Fig. 7 right) that allow to grab pallet by two Allen screws M8x25 STN 021143.52 partially screwed to threaded holes. The handles can be easily fitted over screw heads then pushed to side and secured by lifting pallet. Such system also allow to design implement automatic manipulation of pallets by robot with special effector. 

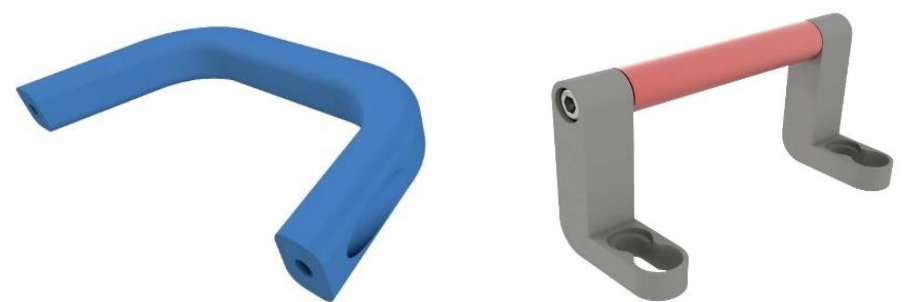

Fig. 7. The fixed handle (left) and the deatachable handle (right)

\section{Conclusion}

The proposed designs are both suitable for production and implementation on CNC machine tool Emco Concept Mill 105 located in laboratory of CNC programing at the Department of Automation and Production Systems, Faculty of mechanical engineering, University of Zilina. The designs were created in order to implement CIM and to upgrade workplace to FMS. Such upgrade is necessary to create the necessary basis for performing complex multicriteria diagnostics in controlled environment.

The proposed pallet system can also significantly improve educational value of existing workplace as it can provide real life example of fixtures for mounting workpieces that are used in industry and present its impact to cycle times in production. The proposed designs shows examples of two different approaches to same problem one of which uses modern fixtures what is also great example of technical advancement. The implementation of pallet system with eccentric cam would require additional testing if it is necessary to add safety catch to prevent release of pallet due vibrations.

All models for these designs including renders and drawings were created in Autodesk Inventor 2017 and their dimensions were verified by stress analysis.

The design of pallet with non-flat shape of pallet with raised ends and dividing of the mounting base into two distinct pieces significantly reduces overall height of pallet system and can be utilized not only on training machine tools but also in industrial production especially on small machine tools with limited workspace or in cases when machined workpiece barely fits into workspace.

This article was made under the support of APVV project - APVV-16-0283 Research and development of multi-criteria diagnosis of production machinery and equipment based on the implementation of artificial intelligence methods.

\section{References}

1. I. Kuric, AJME Journal, 9 (1), 83 (2011)

2. M. Císar, N. Čuboňová, I. Kuric, MATEC Web of Conferences, 94, 01003 (2017)

3. EMCO GmbH, Technical specification Concept MILL 105, http://www.amsarg.com.ar/Productos/EMCO/spec_cm105_en.pdf

4. M. Císar, I. Kuric, N. Čuboňová, Š. Vlček. ASTRJ, 10(31), 80-86 (2016)

5. M. Kandera, Design of clamping system for EMCO Concept Mill 105, (in Slovak), Master's thesis, University of Zilina (2015)

6. Erwin Halder KG, Zero-Point Clamping Systems, http://pdf.directindustry.com/pdf/halderfrance/zero-point-clamping-systems/13708-505599-_2.html

7. ZeroClamp GmbH., General catalogue, https://adobeindd.com/view/publications/1dfb96fd-fc18-4288-92ee-55e46c791fe4/1/ publication-web-resources/pdf/Katalog_A4_neu.pdf 